\title{
Activation levels in Lavukaleve demonstratives: oia versus foia
}

ANGELA TERRILL

\begin{abstract}
The first part of this paper describes an unusual system of anaphoric reference tracking in Lavukaleve, a Papuan language of the Solomon Islands. Lavukaleve has two demonstrative pronouns which can be used to make anaphoric reference in narratives. One of these demonstrative pronouns is used to make anaphoric reference to a semi-activated participant, and the other to an activated participant. The second part of the paper situates Lavukaleve's activation-based system of reference tracking in a general typology of reference tracking. Other languages which have reference tracking systems based on the cognitive status of the referent are discussed, and the close connection between these and obviation systems is pointed out.

Keywords: activation, anaphora, cross-reference, deixis, demonstratives, given-new, obviation, Papuan, pronoun, reference tracking, topic continuity
\end{abstract}

\section{Introduction}

Lavukaleve is a Papuan language spoken by about 2,000 people in the Russell Islands, a small island group within the Solomon Islands. Lavukaleve is one of only a handful of Papuan languages in the Solomon Islands. It is for all practical purposes an isolate, although attempts have been made to relate it, together with the other Papuan languages of the Solomon Islands, to other Papuan languages of island Melanesia (e.g., Wurm 1982, Todd 1975). Lavukaleve also shows relatively little linguistic indication of its long-term proximity with the Austronesian languages surrounding it. Terrill (1999) is a grammatical description of the language. All data on Lavukaleve was collected by the author during a total of 12 months spent in the Russell Islands between 1995 and 2000. All the data used in this paper is natural spontaneously-occurring material.

There are two separate demonstrative pronoun paradigms used to make anaphoric reference to entities in Lavukaleve. The first, oia, is used only for 
anaphoric reference; this function is called tracking, in Himmelmann's (1996) terms, or anaphoric reference in Diessel (1999). That is, oia does not have exophoric functions. The second demonstrative pronoun paradigm is foia, which is used both for anaphoric reference and for exophoric reference. The purpose of this paper is to show the differences between the anaphoric uses of these two demonstrative pronouns.

Briefly, oia is used specifically to track a semi-activated referent, whereas foia is used to track an activated referent. Some correlations can be found between the use of foia and reference to topical entities, last-mentioned, or very recently-mentioned entities, and conversely between the use of oia with non-topics and less-recently mentioned referents, but such features do not completely account for the distinction between foia and oia. In all cases, however, the difference between the use of oia and foia can be accounted for by the notion of activation states.

The activation distinction in the Lavukaleve demonstratives is one which has hitherto not been addressed in descriptions of demonstrative systems, and thus it does not appear in typologies of demonstratives based on those descriptions (e.g., Fillmore 1982, Himmelmann 1996, Diessel 1999). Neither do typologies of reference tracking systems (e.g., Foley \& Van Valin 1984, Huang 2000) address this type of system. Thus the broad aim of this paper, besides description and justification of semi-activation and activation as categories in a demonstrative system, is to suggest a typology of reference tracking systems, of which demonstratives in many languages form a part, which includes as an integral category tracking systems based on the cognitive status of the referent.

Throughout the rest of this paper, the term oia is used as shorthand for the phrase "a demonstrative pronoun from the oia paradigm" and similarly foia is used as shorthand for "a demonstrative pronoun from the foia paradigm". Oia and foia are both the 3rd person feminine singular medial (i.e., neither proximal nor distal) forms of their respective paradigms.

The paper is structured as follows. Section 2 describes the activation-based system of reference tracking in Lavukaleve. In Section 2.1 the means of introducing and tracking referents in Lavukaleve will be briefly outlined, and the two relevant demonstrative pronouns will be introduced. Arising from their different functions, these two demonstrative pronouns have different morphosyntactic properties, which are described in Section 2.2. Section 2.3 is a description of their different uses in reference tracking. After the system is described, the second major part of this paper, Section 3, provides a typological overview: Section 3.1 compares similar systems in other languages and Section 3.2 suggests a framework for a typological categorisation of demonstratives in which activation levels form a part. 


\section{Tracking the cognitive status of referents in Lavukaleve}

\subsection{Introducing and tracking referents in narratives}

Referents in Lavukaleve narratives are introduced with NPs and tracked with pronouns and agreement morphology on verbs and other words. There are three genders in Lavukaleve, which also help to track participants.

The following example comes from the beginning of a story about a group of very stupid people. It introduces this referent, the people, with the NP malav hovariom in the first sentence, then in the next few sentences they are mentioned again only by verbal morphology, focus marking agreement, and the possessive prefix on the noun in the third sentence (all of which are in boldface in the gloss line):

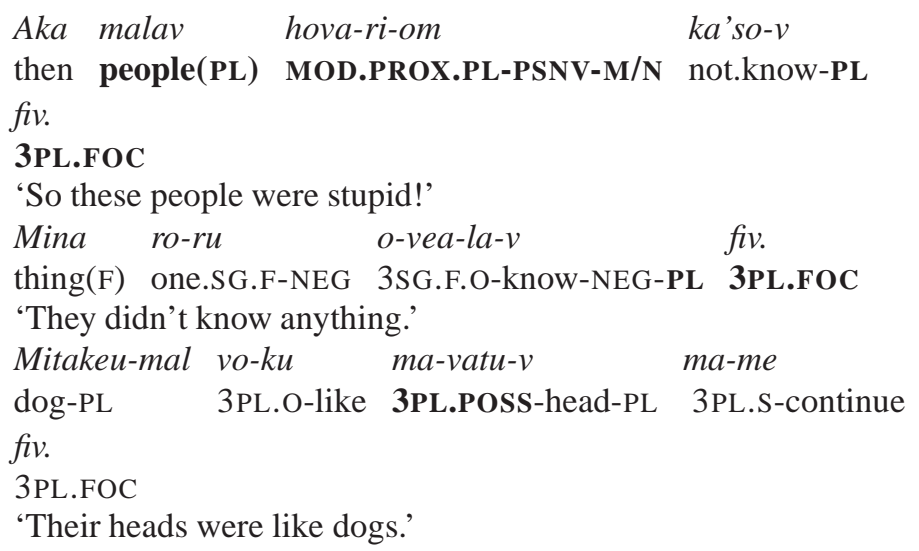

Participants can be tracked with pronouns as well. In Lavukaleve there are two types of demonstrative pronouns which can track 3rd person referents; each one is shown in the following examples. All material referring to the relevant participants is highlighted in the gloss lines:

(2) Participant (the two men) introduced with an NP, then tracked with verbal morphology and a demonstrative pronoun from the oia paradigm (the masculine dual medial form oinala):
Aka airal
lelemal la-o-lai
“ $E$ !
then men.DU two.M 3DU.M.o-3SG.S-tell hey!
'Then he told two men "Hey!'
['The half of the pig that I left is over there in the middle of the road; I covered it and left it.]'1

1. The bracketed part of the translation refers to irrelevant material which has been omitted to save space. 
Feu e-ma-ila" la-o-lai.

go.up 3SG.N.O-take-PCTIMP.DU 3DU.M.O-3SG.S-tell

'You two go up and take it" he told them.'

Hano oinala hamus ga e-na

then SEMIACT.MED.M.DU evening(N) SG.N.ART 3SG.N.O-in

lo-feu-i.

3DU.POSS-go.up-PSV

'So those two, in the night they went up.'

(3) Participant (a group of boys) introduced with an NP, then tracked with verbal morphology and a demonstrative pronoun from the foia paradigm (the plural proximate form fova):

Galeng vasa va ma-vau.

boys(PL) group PL.ART 3PL.S-go.out

'The boys go out.'

Lake ga forsoi-re fova vau

$\operatorname{road}(\mathrm{N})$ SG.N.ART 3SG.N.O-follow-NF ACT.PROX.PL go.out

$m e-v$.

HAB-PL

'They follow the road and go out.'

In example (2) above, a demonstrative pronoun from the oia paradigm is used to make pronominal reference to the argument being tracked. A foia demonstrative pronoun could not be used here. In example (3), foia is used and a demonstrative pronoun from the oia paradigm could not be used. The purpose of this paper is to account for the difference between these two demonstrative pronouns, by showing that the circumstances in which oia is used and those in which foia is used are different. Both demonstrative pronouns are used for anaphoric reference, but they have different pragmatic functions, which account for their different distribution.

A full description of reference tracking in Lavukaleve would take into account the use of all these morphological means of tracking participants, including the principles determining the presence/absence of the demonstratives. However, the motivation of the present study is a smaller question, namely: given that a demonstrative pronoun will be used to track a participant, how can we predict which demonstrative pronoun it will be?

\subsection{Morphosyntactic differences between oia and foia}

Both foia and oia are demonstrative pronouns. There are no 3rd person PERSONAL pronouns in Lavukaleve, although foia and oia are possible candidates (there are, however, 1 st and 2nd person personal pronouns). Himmelmann (1996: 211-215) has a methodology for distinguishing 3rd person pronouns 
Table 1. Paradigm of foia

\begin{tabular}{llllll}
\hline & & Proximal & Medial & Distal 1 & Distal 2 \\
\hline Singular & Masculine & fona & foina & feana & foana \\
& Feminine & fo & foia & fehea & fohoa \\
& Neuter & foga & foiga & feaga & foaga \\
Dual & Masculine & fonala & foinala & feanala & foanala \\
& Feminine & fol & foiaol & feheaol & fohoaol \\
& Neuter & fogala & foigala & feagala & foagala \\
Plural & & fova & foiva & feava & foava \\
\hline
\end{tabular}

from demonstratives, but even he admits that it is difficult to apply, and certainly my data does not contain such examples as would be necessary for a rigorous distinction to be made. Foia and oia are considered demonstrative pronouns rather than personal pronouns largely because they are marked for degrees of distance (even though only marginally in the case of oia). The grammatical category of distance is more usually associated with demonstratives than with personal pronouns.

Foia has four stem forms. The first three mark degrees of distance: proximal, medial, and distal; and the fourth form (glossed Distal 2) is used for hypothetical referents. The actual use of these terms in narratives has more to do with the speaker's representational point of view in the story, or apparent viewpoint, than with pure distance from the speaker.

The forms of the oia deictic are identical to those of foia, except for the lack of initial consonant. Note also that the oia stem only has two degrees of distance, proximal and medial. In fact, the proximal degree is marginal; only the singular neuter form has been found, very rarely. In elicitation, speakers were reluctant to suggest any other forms, and were even reluctant to accept the singular neuter form. The very existence of a proximal form is anomalous in any case as oia is never used exophorically, so it is unclear what the nature of the contrast would actually consist in. Foia is about twice as common in spontaneous narratives as oia. The paradigms for foia and oia are given in Tables 1 and 2.

There is a further paradigm, hoia, which is a demonstrative modifier 'this'. Its forms are identical to those of foia, but with an initial $h$ instead of $f$. Typically it occurs inside NPs functioning as a modifier of a head noun. Oia and foia, by contrast, occur as heads of NPs.

Oia has the morphological form of a demonstrative pronoun (i.e., in terms of its gender/number/distance parameters). But syntactically it functions as a noun rather than a pronoun. For instance, foia, like 1st and 2nd person pro- 


\section{Angela Terrill}

Table 2. Paradigm of oia

\begin{tabular}{llll}
\hline & & Proximal & Medial \\
\hline Singular & Masculine & - & oina \\
& Feminine & - & oia \\
& Neuter & $($ oga $)$ & oiga \\
Dual & Masculine & - & oinala \\
& Feminine & - & oial \\
& Neuter & - & oigala \\
Plural & & - & oiva \\
\hline
\end{tabular}

nouns, can function as a resumptive pronoun (that is, following straight after an NP with which it is coreferent, in apposition to that NP), whereas oia cannot. Further, oia can itself be the head for a resumptive pronoun, whereas foia and other pronouns cannot. Also, unlike other pronouns, oia can function as the head of a relative clause. These points are illustrated below.

In example (4), foia is used resumptively. Compare this with example (5), in which a 1 st person pronoun $(e)$ is used in the same resumptive function. It is not possible for oia to be used in this way:

$$
\begin{array}{lccll}
\text { Ae } & \text { fale-re } & \text { a-e-kako-meon } & \text { ta } & \text { tagio } \\
\text { go.up } & \text { stand-NF } & \text { 3SG.M.O-SBD-look.out-SURP just } & \text { snake(F) } \\
\text { ru } & \text { la } & \text { foia } & \text { fufu-re-ne } &
\end{array}
$$

big.SG.F SG.F.ART ACT.MED.SG.F lie.down-NF-IMPF

'He stood up, looked around, and the big snake, it was lying there.'

$$
\begin{aligned}
& \text { Aka malav } \boldsymbol{e} \text { vuti-v foe linga } \\
& \text { then people(PL) 1PL.EX be.many-PL 1PL.EX.FOC song(M) } \\
& \text { a-fu-ne fi e-ngoa Sunday } \\
& \text { 3SG.M.O-sing-IMPF 3SG.N.FOC 1PL.EX-stay Sunday(N) } \\
& \text { e-na } \\
& \text { 3SG.N.O-in }
\end{aligned}
$$

'There were lots of us singing, on Sunday; lit., the people we were many, singing on Sunday.'

However, oia itself can be the NP for which foia is the resumptive pronoun, as in examples (6) and (7):

$$
\begin{array}{llll}
\text { Oia } & \text { foia } & \multicolumn{2}{c}{\text { ao-re-ne }} \\
\text { SEMIACT.MED.SG.F } & \text { ACT.MED.SG.F } & \text { go.in-NF-IMPF } \\
\text { o-kala } & \text { la } & \text { vo-re } & \text { heana } \\
\text { 3SG.POSS-mother(F) } & \text { SG.F.ART } & \text { come-NF } & \text { MOD.DIST 1.SG.M }
\end{array}
$$


hano soko-m

then laugh-SG.M

'The other one, she gets down, his mother comes, then the [younger boy] laughs.'

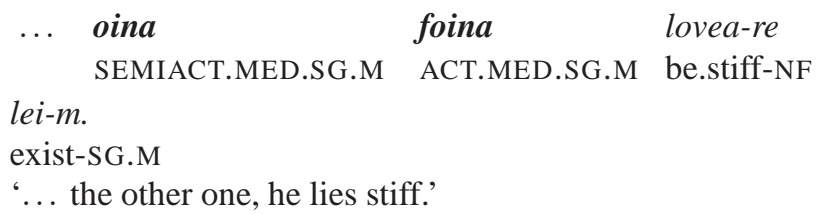

Foia, like 1st and 2nd person pronouns, cannot function as the head of a relative clause, but oia, like nouns, can, as in example (8):

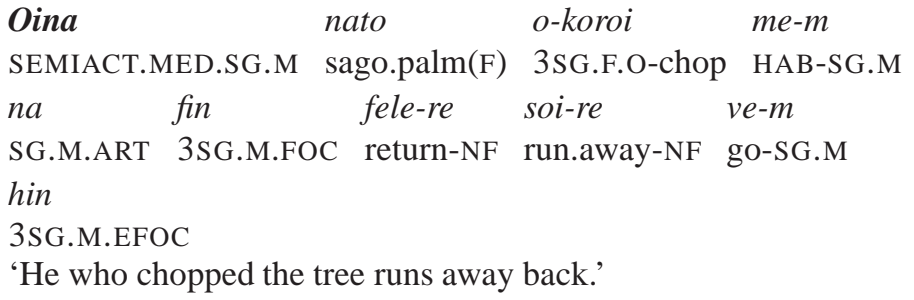

\subsection{Pragmatic differences between oia and foia}

Both oia and foia are used for anaphoric reference, but they have different domains of use. Within its general anaphoric function, oia is used to make reference to a semi-activated entity, whereas foia, when it is used anaphorically, always makes reference to an activated entity.

The term "activation" is taken from Chafe $(1987,1994)$. Chafe distinguishes between three levels of activation. That is, out of all the many concepts people have in their minds at any one time,

[a]n active concept is one that is currently lit up, a concept in a person's focus of consciousness. A semi-active concept is one that is in a person's peripheral consciousness, a concept of which a person has a background awareness, but which is not being directly focused on. An inactive concept is one that is currently in a person's long-term memory, neither focally nor peripherally active. (Chafe 1987: 25)

Activation is a matter of degree. An entity, once active, gradually loses its active status over time. Lavukaleve encapsulates the degree of activatedness of a pronoun referent with the distinction between foia and oia. Foia is used to refer anaphorically to participants which are active. Oia is used to refer anaphorically to participants which have become somewhat less activated; 


\section{Angela Terrill}

these are semi-active entities, in Chafe's terms, or semi-deactivated and accessible in Dryer's (1996: 481-482) terms: semi-deactivated entities being those which "were previously fully activated but [...] have faded in activation, while accessible entities are ones which need not have been previously activated but which differ from fully nonactivated entities due to their association with activated entities". 2

Given the nature of activation, one would expect the referents with the highest degree of activation (i.e., those referents upon which attention is most strongly focussed) to have some or all of the following features: they should have low anaphoric distance (in terms of Givón (ed.) 1983); they should have no interfering context (in the terms of Givón (ed.) 1983 and Lichtenberk 1988); and the referent should be a major participant in the discourse, for instance. Kibrik (1996) mentions a list of hypothesised "activation factors", which includes similar phenomena. Ariel's (1988: 65) definition of accessibility includes similar factors: distance; number of competitors for role of antecedent; importance of topicality for antecedent assignments; role of frames in identifying antecedents (although see Dryer (1996: 482; quoted above) for the difference between accessibility and activation).

This paper aims to show that features one would expect to be associated with activation states (derived from Givón, Kibrik, Ariel, and others) are associated with the distinction between foia and oia; but that each of these features in itself does not completely account for the use of foia/oia, although each one goes some way towards it: and ultimately, that invoking the concept of activation states is nonetheless a revealing way of accounting for the oia/foia distinction.

The major argument of this paper, that the degrees of activation which have

2. Note that Dryer (1996: 482) introduces a fourth level of activation, namely FOCUS OF ATTENTION: "even among entities that are fully activated, some may be particularly activated in the sense that they are the FOCUS OF ATTENTION". So Dryer's four levels of activation are as follows:

Focus of attention $>$ activated but not focus of attention $>$ recently activated but now semi-deactivated / accessible to activation $>$ nonactivated.

Dryer himself notes that "to what extent these four levels have any significance beyond being arbitrary divisions is not clear" (1996: 482). This is an empirical point which in fact proves quite problematic. If Lavukaleve were analysed under Dryer's system, entities referred to with foia would correlate with the "focus of attention"; and oia with entities which are activated but not the focus of attention, or recently activated but now semi-activated, or accessible to activation. However, it is not clear that the concept of "focus of attention" is necessary; or indeed if it used how to justify it. The difference between foia and oia can be accounted for simply with the notion of activation alone, which, as I understand it, encompasses attention. For an entity to be fully activated, and, in the case of Lavukaleve, referred to with foia, it must be in the focus of attention. Any situation less than this I would call semi-activated, rather than activated but with less attention on it; Lavukaleve would mark such situations with oia. 
Table 3. Gundel et al.'s (1993) Givenness Hierarchy

\begin{tabular}{|c|c|c|c|c|c|}
\hline & Activat & Familic & $\begin{array}{l}\text { Uniquely } \\
\text { identifiable }\end{array}$ & $>$ Referential & $\begin{aligned}> & \text { Type } \\
& \text { identifiable }\end{aligned}$ \\
\hline it & $\begin{array}{l}\text { that } \\
\text { this } \\
\text { this } \mathrm{N}\end{array}$ & that $\mathrm{N}$ & the $\mathrm{N}$ & indefinite this $\mathrm{N}$ & $a \mathrm{~N}$ \\
\hline
\end{tabular}

been posited largely on theoretical grounds are in Lavukaleve represented morphosyntactically, finds its place in the same general area as the work of Gundel, Hedberg, \& Zacharski (1993), among others. Gundel et al. posit a Givenness hierarchy, a hierarchy of cognitive states, which are represented, they claim, by different referential forms in languages. The hierarchy, with the corresponding English referential forms, is shown in Table 3.

Activation is widely considered to have various levels, as the sources cited above indicate. The aim of this paper is to show that there are formal subcategories, in Lavukaleve at least, within the functional subcategories of activation: for Lavukaleve (and presumably therefore for at least some other languages) Gundel et al.'s Givenness hierarchy must be extended to show two activation statuses, fully activated and semi-activated, realised morphosyntactically by two corresponding referring expressions. The rest of this section describes the use of the two referring expressions in Lavukaleve.

Oia is used in situations in which there is more than one main participant, to reactivate an earlier discourse topic that has been replaced by a more recent one. Chafe makes the point that more than one entity cannot be activated at any one time. As one entity is activated, another loses its activation. Oia makes overt the change in activation levels caused by the switch of attention between participants.

Some examples should make the functioning of the two demonstrative pronouns in Lavukaleve clearer. Most commonly, foia is used to refer anaphorically to an entity mentioned in the same or immediately prior intonation unit, either resumptively or not, as in the next two examples:

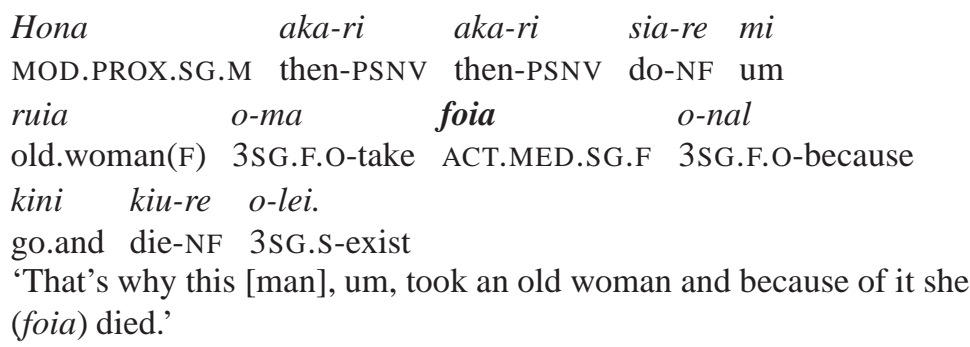




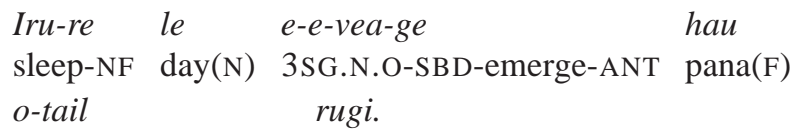

In all cases, foia is used to make anaphoric reference to an entity which was recently (i.e., in the last couple of sentences) mentioned, and to which the speaker is paying attention.

Often such an entity is a topic of the discourse. In the next example, the referent referred to throughout as 'he' is the boy who the story is about. He is the topic of the narrative. When he is referred to here, the story is already about this boy, there are no other possible referents, and foia is used:

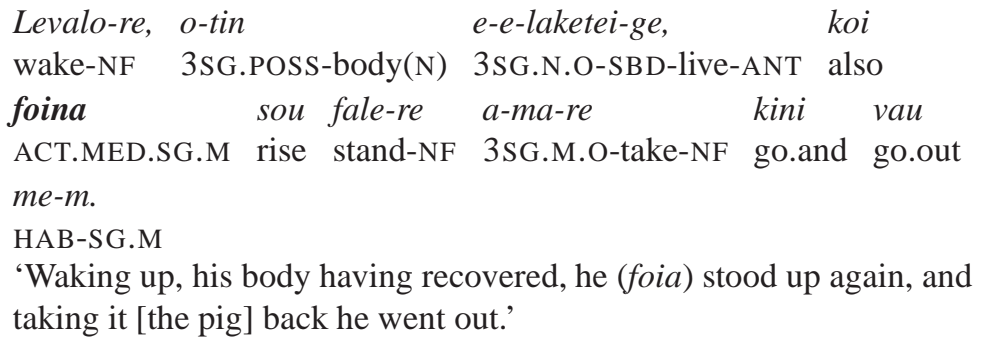

By contrast, oia is used to make anaphoric reference to an entity which has not been mentioned in recent discourse or is not uppermost in the speaker's and addressee's minds. For example, the following could be said about someone who had been previously taking part in the conversation but has since left:

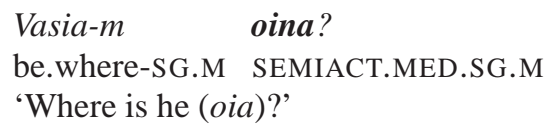

The feature of a referent not being uppermost in the speaker's and addressee's minds usually entails that the referent was not the last-mentioned participant. In the next example, there are two main participants, two men. The first

3. Pana is a root vegetable.

4. Foiga 'it' refers here to the whole event of the house appearing for the pana. 
participant is the man who put his hand in the basket (mentioned here in the first word roa). The second man, the house owner, is first mentioned in this passage with oina.

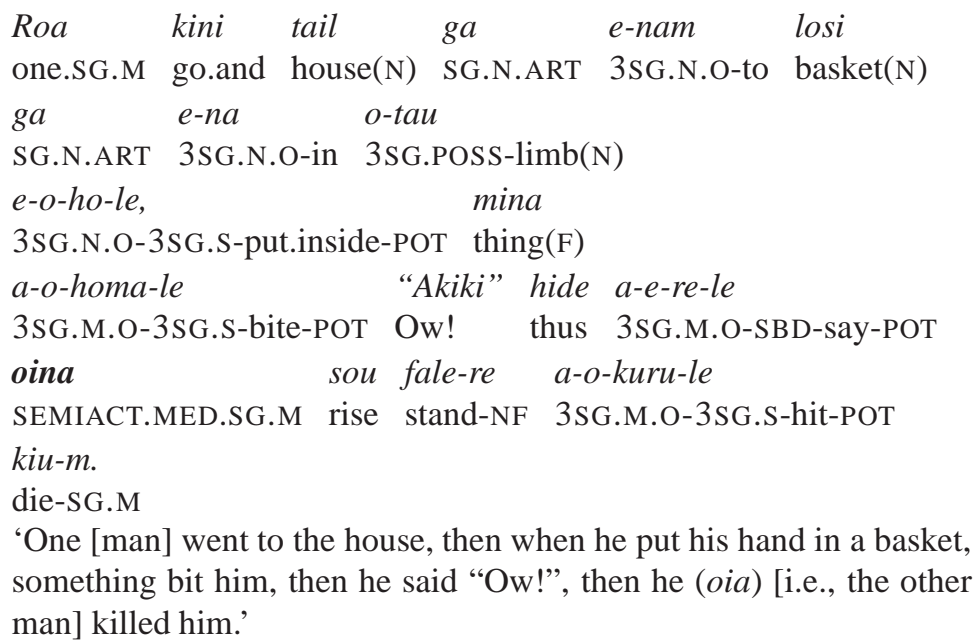

The second man, when he is first mentioned here, is not the participant to whom the most attention is currently being given; rather, the first man is. If the other demonstrative pronoun, foia, were used in this sentence instead of oia, it would have to make reference to the first man, not the second.

Another reason why an entity is not uppermost in speech participants' minds is that it has not been mentioned for a long time. Oia can be used to make reference to such an entity. In the following example, oia is used to make reference to a woman, a major participant of the story who has, however, not been mentioned for the last ten sentences:

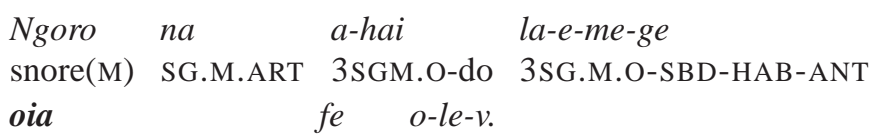

'He was snoring, and she (oia) went and saw them [him and the children].'

In example (13) above, the first man, the one who put his hand in the basket, is the topic (in the sense of Givón 1983, among others) of that part of the story, and the second man, the one referred to with oia, is not a topic. However, it is not the case that oia is used to refer to non-topics and foia to topics. Oia can be used to make reference to a topical entity, but only if that entity is not the one which currently has the most attention being given to it; that is, 
under the current analysis, oia is used to make reference to a deactivated entity, irrespective of whether that entity is or has been a topic. This can be seen in the following examples.

The next example refers to two groups of people, both topics at this stage of the story: a group of would-be-thieves and a group of villagers. The villagers go to sleep, and the would-be-thieves, seizing their chance, prepare to go and steal from them:

$$
\begin{aligned}
& \text { Iru vo-e-me-ge iru vo-e-me-ge iru } \\
& \text { sleep 3PL.O-SBD-HAB-ANT sleep 3PL.O-SBD-HAB-ANT sleep } \\
& \text { vo-e-me-ge oiva "Bae!" } \\
& \text { 3PL.O-SBD-HAB-ANT SEMIACT.MED.PL let's.go } \\
& \text { 'They slept and slept and slept, then the others (oia) said "Let's go!"' }
\end{aligned}
$$

Both groups are topical. In this sentence, the sleeping villagers are referred to first with verbal morphology, then the would-be-thieves are mentioned through the use of oia. If foia were used here it would mean that the same people who were sleeping then said "Let's go!". The fact that oia is used shows that the reference is not to the sleeping villagers, but to another group of people; the only other possible referent being the would-be-thieves. Under the current analysis, the reason why oia is used here rather than foia is that to use foia would be to make reference to the most activated entity, which is here the sleeping villagers, whereas using oia would not entail this.

The same thing can be seen in the next extract. This part of the story is about one man and a group of people. In the first sentence, the people go up to the bush. Then in the second sentence, our attention is turned back from them to one man, and the oia demonstrative pronoun is used. In the third sentence, the group of people are once again mentioned, referred to with oia. The fourth sentence shows a continuation of the people as the active entity and the topic, with reference made using verbal morphology.

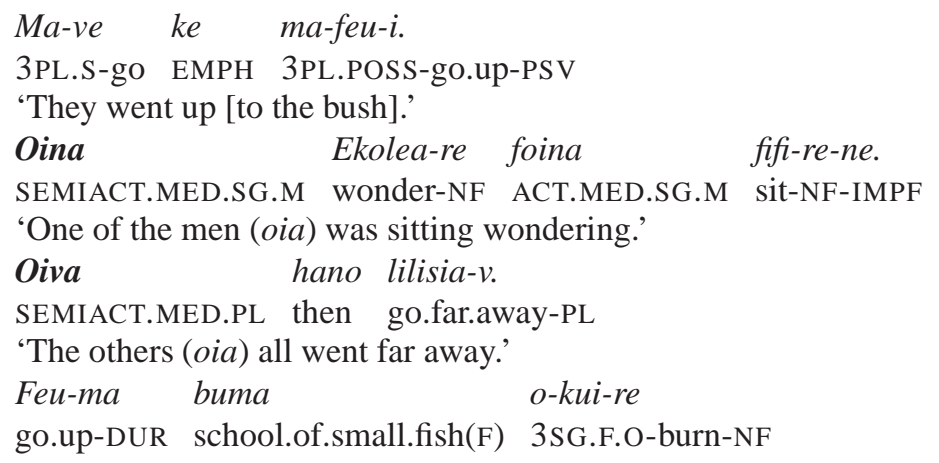


$o-u-n u v$.

3SG.F.O-eat-PRES.PL

'They went, and cooking their little fishes, they (start) eating them.'

Consider also the next extract, from a story about two men, one at the top of a tree and the other at the bottom, and a group of people distributed around in between, passing messages between the two men. The man at the top is supposed to pick a coconut to send down to the man at the bottom, but as he explains here, the coconut tree is just a stalk, with no leaves or fruit. This extract is the conversation passed between the two men.

$$
\begin{array}{llll}
\text { Hide lai-n me-m } & \text { na } & \text { a-e-re-ge } \\
\text { thus top-LOC } & \text { SPEC-SG.M } & \text { SG.M.ART } & \text { 3SG.M.O-SBD-Say-ANT } \\
\text { o-ma-kelago-ri-ge } & \text { o-foa. } \\
\text { 3SG.F.O-3PL.S-go.over-CAUS-ANT } & \text { 3SG.S-go.down }
\end{array}
$$$$
\text { 'Then the one at the top sent his word down.' }
$$

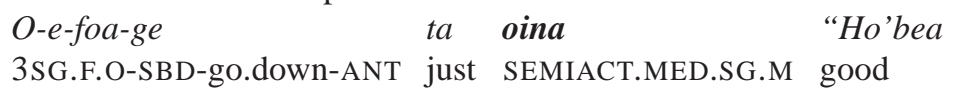$$
\text { fi” o-re. }
$$$$
\text { 3SG.N.FOC 3SG.S-say }
$$$$
\text { 'It going down, the other man (oia) said "It's all right!", }
$$$$
\text { O-kelago-ri-ge leta aka oina }
$$$$
\text { 3SG.F.O-go.over-CAUS-ANT but then SEMIACT.MED.SG.M }
$$$$
\text { feiria-re haikio la o-hai. }
$$$$
\text { be.tired-NF shout(F) SG.F.ART 3SG.S-do }
$$

'The talk went back up, then other man (oia) on top got sick of it and shouted.'

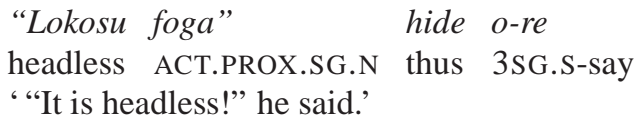

In the first sentence in (17) above, the man at the top is referred to with the NP lain mem na 'the top one' and verbal morphology, which establishes his activation. In the second sentence, there is another man mentioned, the man at the bottom, mentioned with oia. Before this mention he was not the currently most activated entity; the man at the top who was just talked about was. With his mention with oia he becomes activated, however, and in the third sentence, the top man is referred to again, this time with oia. Under the current analysis, this is because he is no longer the activated entity; the bottom man is. In the fourth sentence the top man remains as the referent who has our attention.

These examples show that the difference between foia and oia is not that foia is used to refer to topics and oia to non-topics. Rather, both can be used to refer to topics, but foia can only be used for activated entities, whereas oia can 


\section{Angela Terrill}

only be used to refer to semi-activated entities. This is the case irrespective of the topical or non-topical status of the referent.

Although it is frequently the case that foia is used to refer to the last-mentioned entity, and oia to an entity which was not the last-mentioned, the difference between foia and oia cannot be stated simply in terms of last or non-last mention. That is, it is not possible to state a mechanical rule that Lavukaleve's demonstrative pronoun system looks at the last-mentioned entity, and if it is the same as the current entity, foia is used, and if it is different, oia is used. The following examples show this.

In the next example, foia is used in the last sentence to refer to sokil 'boat', first mentioned in the first sentence. However in the fourth sentence, two other entities are also mentioned; 'they' and 'us', both referred to with verbal morphology. The entity referred to as 'us' is actually the topic of the story. In the fifth sentence, however, the boat is again referred to, with foia.

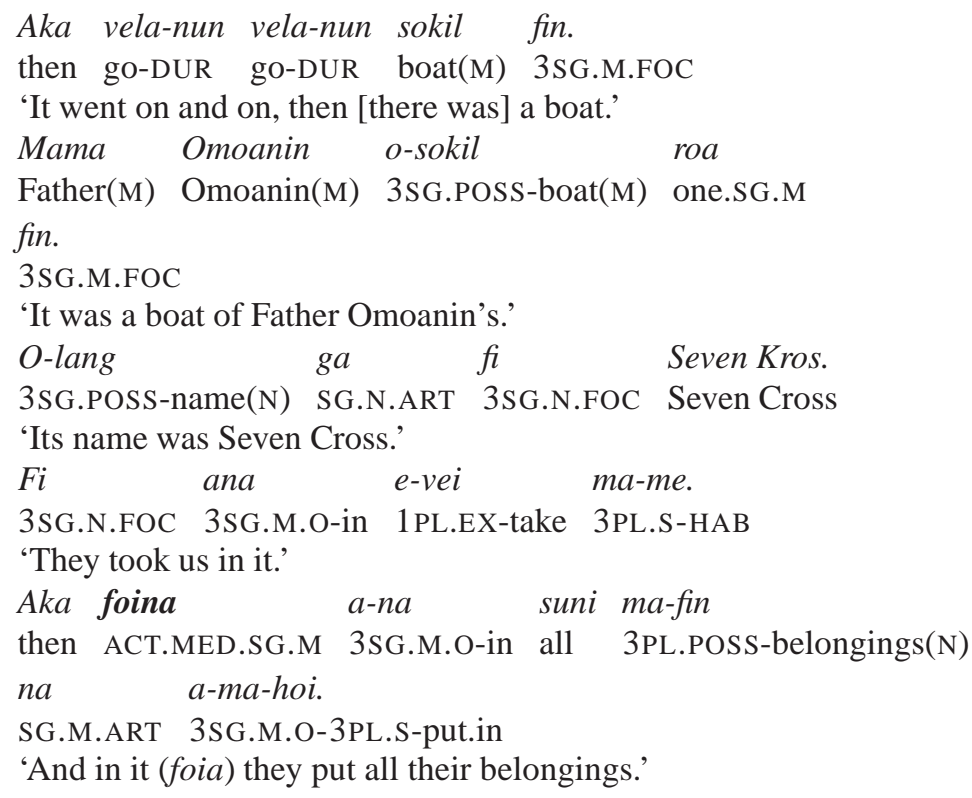

So in the last sentence foia is used to refer to the boat, not oia. This is despite the fact that there is an intervening mention of the major discourse topic 'us', and other potential important referents. However, the whole narrative centres around the boat: the first sentence introduces it, the second says who it belongs to, the third gives its name. The fourth says who travelled in it, and the fifth says what else went in it. The whole sequence has been about the boat, and despite other referents intervening, the boat is still what the fifth sentence is about. Attention throughout the whole sequence has been on the boat; and, 
if the current analysis is correct, activation has stayed with the boat, and this accounts for the use of the foia demonstrative pronoun here.

A similar situation occurs in the next example, in which foia is used to refer to a man, Soana, even after an intervening mention of two entities: 'people' and 'them (the fish)', which is the topic of the section. In this sequence, the speaker is interested in Soana, not in the other entities. The first sentence introduces Soana as subject, the second tells what Soana's role was, and the third shows Soana's current relationship to the fish. In all three sentences, the attention is on Soana. The activation analysis accounts for the use of foia, rather than oia, despite the fact that foia is making reference to an entity which was not the last-mentioned.

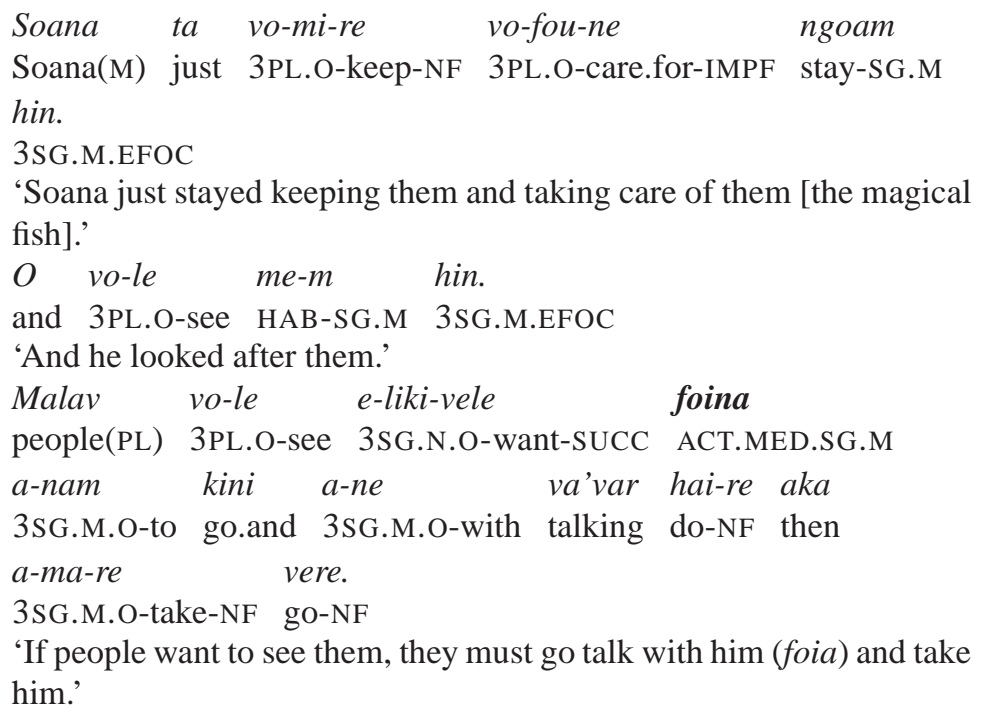

These examples suggest that the foia/oia system does not look simply at which referent was the last-mentioned, but rather looks at which of the available referents is the most activated. Usually the highest level of activation correlates with the most recent mention, and thus the two possibilities generally coincide, but the above examples have shown that this is not always the case. The crucial parameter is activation, not the property of being last-mentioned.

The fact that the central parameter is not simply the property of being lastmentioned also points to another important factor. Activation state is not the same phenomenon as anaphoric distance. Something at a close anaphoric distance is more likely to be activated, but it is not the case that the referent at the smallest anaphoric distance can be mechanically computed as being the referent most activated. The above examples (18) and (19) each show a participant 
referred to by foia, the demonstrative pronoun used for activated referents under the present analysis, even though the antecedent of the referent is not the closest possible antecedent, in terms of anaphoric distance. This is not to suggest that anaphoric distance plays no role in activation states; but rather that there is not a simple correlation between the smallest anaphoric distance and the use of the activated demonstrative pronoun.

Some of the above examples have shown one of the most characteristic functions of oia: oia is most often seen in long sequences making reference to two topical entities, tracking the change in activation levels between the two topical entities in a leap-frog fashion; as one entity gains activation the other loses it. This idea is exemplified further in the next extracts.

In the following excerpt (20), there are two sets of participants: a boy and a group of giants. The oia demonstrative pronoun is used when the speaker switches between mentions of the two sets of participants. In the first sentence, the giants are mentioned with a full NP, which may be taken as establishing their activation. In the second sentence, the first clause has the giants still as active participant. Then in the second clause the boy, who was last heard about two sentences back as lying in wait for the giants, is mentioned (and oina is used to refer to him). So the boy is now the most active participant, and thus the activation of the giants recedes. The third sentence starts with a similar headtail linkage, with the boy still as active participant, then the giants are again mentioned, referred to with oiva. The giants then become the active participant of the next few clauses:

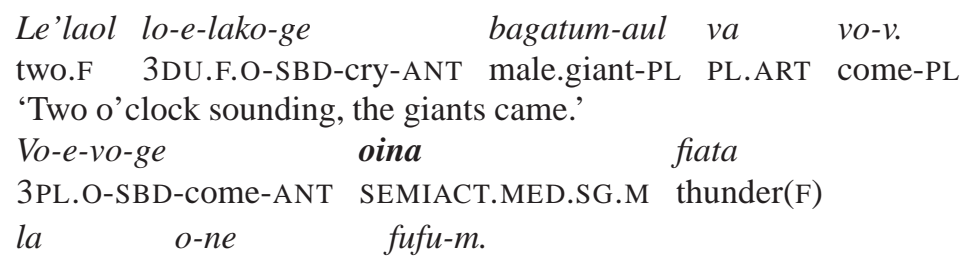




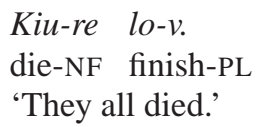

Similarly, consider the following example. The older brother goes out hunting with his mother, the younger brother stays at home, and then the older brother comes back and refuses to give the younger boy any food. In the first sentence of (21) the older brother is given a full NP mention, which establishes him as activated. In the second sentence, the younger brother is mentioned again, and the oia demonstrative pronoun is used. He remains as the main participant of the third sentence, referred to with verbal morphology. In the fourth sentence, the elder boy is mentioned again. Under the current argument, the elder boy supersedes the younger boy as most activated, as he is mentioned again with oia:

$$
\begin{array}{lllll}
\text { Vau-re } & \text { vo-kuru-re koi aka-ri } & \text { nikol me-m } \\
\text { go.out-NF } & \text { 3PL.O-hit-NF also then-PSNV first SPEC-SG.M } \\
\text { na } & \text { aka-ri tin o-muan } & \text { tin. }
\end{array}
$$

SG.M.ART then-PSNV only 3SG.POSS-self only

'Going out, they (the mother and oldest boy) killed [fish], and again the older boy did the same thing; [ate] by himself.'

Oina ngoa-ne.

SEMIACT.MED.SG.M stay-IMPF

'The other one (oia) just stayed.'

Vo-u-la lei-m fin.

3PL.O-eat-NEG exist-SG.M 3SG.M.FOC

'He didn't eat them [the fish].'

Kini hau-vele oina vo-lai-re

go.and go.ashore-SUCC SEMIACT.MED.SG.M 3PL.O-disallow-NF

ta hi lo-me.

just do/say 3SG.S-HAB

'When he came ashore, he (the other one) (oia) disallowed [the fish] [to the younger boy].'

The last few examples have shown oia switching activation between referents. It should be pointed out, though, that the primary function of oia is not as a switch-activation marker, along the lines of a switch-reference marker. Rather, its primary function is to make reference to an entity which is not currently the most activated one. Because the property of being currently the most activated is a dynamic one, the currently-most-activated entity changes with every mention, and so oia by its very nature tends to be used in situations in which activation switches between referents. 


\section{Angela Terrill}

Note that in all these examples, it is clear that while the demonstrative pronouns oia and foia track changes in activation levels, other linguistic material does not overtly track this distinction. Verbal cross-referencing morphology and other agreement material is blind to the difference between activated and semi-activated referents. By this I mean that while demonstratives must distinguish between activated and semi-activated referents, both types of referent can also be cross-referenced with verbal markers, which are the same whether the referent is activated or not.

One important issue arises from this statement: given that verbal crossreferencing material exists, and given that in Lavukaleve, as in other languages, it is used in circumstances of high activation, there appears to be an overlap with the function of foia. In fact, one could wonder why speakers use foia at all, given that it seems to have much the same function as verbal crossreferencing. However, even though foia and verbal cross-references have a similar discourse function, they contain different information. Foia contains information on distance from the speaker (as mentioned in Section 2.2); also, foia forms are marked for gender and number, whereas some combinations of verbal cross-referencing affixes do not mark person or gender, and many are ambiguous between various person/gender/number combinations. Further, verbal affixes are grammatically constrained and cannot appear in some circumstances. For example, subject cross-referencing prefixes cannot appear inside clause chaining constructions. In certain focus constructions, constructions using the habitual auxiliary, subordinate-dependent clauses and serial verb constructions, verbal cross-referencing is highly constrained, and in some circumstances cannot appear at all (Terrill 1999: 222-229). However, foia, being a nominal head, has far more freedom, and can in principle appear in any clause type. It is in these differences, rather than in their discourse functions per se, that the use of foia versus verbal cross-referencing can be understood.

Returning to the pragmatic functions of oia, it is important to point out that oia is not simply a contrastive pronoun. Its function is not to contrast one entity with another or to pick out one entity from a group of referents. Fillmore (1982: 54) mentions a deictic in Bakwiri, used for what he calls "serial order", generally translatable as 'the other'. This is not the function of oia in Lavukaleve. Oia is not used for listing or contrasting two or more elements. For this function, ro 'one' is used, thus ro ... ro means 'one ... the other'. Oia is often best translated into English with 'other', but this is just an attempt to capture some aspects of this rather complex pragmatic function in one English word. Similarly, the function of oia is not the same as Nunggubuyu's contrastive pronoun, which switches from one topic to a new one. Commonly this pronoun is used for when different participants are performing parallel actions; so something like "X, on the other hand ..." (Heath 1983: 135). It is also used for what Heath calls role reversal; when subject and object roles are reversed 
across two sentences with a similar verb; thus, "The man hit the woman and she hit him back." (Heath 1983: 135-136). Clearly this is quite different to Lavukaleve's foia/oia distinction.

\section{A typological perspective}

\subsection{Similar systems}

The previous sections of this paper have argued for a reference tracking mechanism in Lavukaleve based on the cognitive status of an NP referent. The aim of this section is to show that the type of system which tracks referents according to their cognitive status is not unknown in the literature, but it has not hitherto been recognised as a reference tracking type in its own right. First it will be shown that this type of system has been described for a few other languages, and subsequently the analysis will be embedded in a typology of reference tracking systems. It will be shown that this type of reference tracking shares fundamental similarities with obviation systems, although there are important differences.

There are other languages with reference tracking systems that can be described as tracking the cognitive status of referents. A similar system to Lavukaleve's foia/oia distinction is that discussed by Lichtenberk $(1988,1996)$ in To'aba'ita, which is an Oceanic language spoken on Malaita in the Solomon Islands, relatively close to where Lavukaleve is spoken, although the two languages are unrelated. In To'aba'ita, there are two anaphoric demonstratives 'eri and baa, both of which can be translated as 'the aforementioned'. Lichtenberk describes them as differing in terms of accessibility, which he defines as anaphoric distance: 'eri is used when the entity referred to is very nearby in the previous discourse, and baa is used when the entity referred to was mentioned further away in the discourse. Anaphoric distance itself has a number of components; apart from recency of mention and last mention, there are other factors such as the presence or absence of direct speech and other discourse which intrudes upon a narrative stretch. This system is very similar to Lavukaleve's demonstratives in pragmatic function, but Lavukaleve looks not at anaphoric distance, but rather at which of the major participants is being paid the most attention to. It was shown above that recency of last mention is implicated in the use of foia versus oia, but is not criterial.

Another system of reference tracking which tracks the cognitive status of referents is described for Dutch. In a recent paper Comrie (1997) describes how Dutch demonstrative pronouns contrast with personal pronouns in their anaphoric use (and Russian, German, and Afrikaans are mentioned as making a similar distinction). The difference between making anaphoric reference with a personal pronoun or a demonstrative pronoun is to do with topic continuity, and in particular with making reference to expected versus unexpected 
antecedents. The demonstrative pronoun refers to the less expected antecedent where there is a choice. The topic would be the expected antecedent, so in fact the demonstrative pronoun is used to refer anaphorically to a non-topic referent. So this is similar to what Lavukaleve's system is doing: if one assumes that activated participants are more expected as anaphoric referents, then the use of foia versus oia could be analysed in terms of anaphoric reference to expected versus unexpected participants. However, the terms in which the Dutch system operates are different; the Lavukaleve system refers to topics not per se, but only, like all other types of referents, inasmuch as they are activated or not. There are other important differences. The pronouns themselves in Dutch carry a very different functional load than pronouns in Lavukaleve, as Lavukaleve has extensive cross-referencing on predicates, and Dutch does not. Further, in Dutch, a personal pronoun is always possible instead of the demonstrative pronoun for anaphoric reference, but in Lavukaleve it is not possible to use foia where oia would be appropriate, and vice versa.

The reference tracking systems in Dutch and To'aba'ita, while very different from each other, and from that of Lavukaleve, have their most basic feature in common: that each of them operates by means of tracking the cognitive status of a referent through a discourse. Other languages, too, have such a tracking system. For example in Kiowa (Watkins 1990), the difference between tracking referents with full NPs versus with zero anaphora is based on their "topicworthiness", which Watkins equates to prominence or importance: "definite nouns referring to participants are more likely to occur when two referents which are roughly equal in topic-worthiness are interacting directly" (Watkins 1990: 425).

\subsection{Cognitive status and the typology of reference tracking}

Huang (2000), following Foley \& Van Valin (1984), provides a typology of reference tracking systems by dividing them into the following categories: gender systems, which track referents according to an inherent feature of the referent; obviation, which tracks referents according to their relative salience in the discourse; switch-reference, which tracks the syntactic status (typically subjecthood) of a referent; switch-function (i.e., passive, anti-passive constructions etc.), which tracks the semantic function of a referent; and inference systems, under which referents are tracked not by overt morphosyntactic means but by means such as zero anaphora and pragmatic rules including inference.

This typology does not really take into account systems such as those described for Lavukaleve, as well as Dutch and To'aba'ita. These systems track reference by cognitive status, which is not an inherent feature of a referent like gender, but rather is assigned to a referent based on discourse-linguistic context, and in this sense is parallel in nature to syntactic status or semantic 
status. Unlike switch-reference or switch-function systems, but similar to gender and obviation systems, the cognitive status system tends to operate across a discourse rather than a sentence. (For a discussion of these parameters, see Comrie's (1989) typology of reference tracking systems, which classifies reference tracking systems according to two parameters: whether the feature by which a referent is tracked is inherent or assigned; and whether the feature tracked is a local feature, i.e., one which is confined to a clause or sentence, or a global feature, i.e., one which can remain stable throughout an entire text.)

Cognitive status systems appear most closely linked to obviation systems, and it is worth exploring closely the relationship between them. Proximate/ obviative systems are well known in the literature from Algonquian languages. In Blackfoot, for example, if there are two or more animate nouns in the same sentence, one can be cross-referenced as proximate (major 3rd person), and the other(s) as obviative (minor 3rd person) (Frantz 1991: 11-12). The speaker can choose which is which, based on which is preferred as the more prominent participant in the discourse. A similar system is found in Kutenai, a language isolate from British Columbia: if there is more than one 3rd person participant in one clause, one is marked as proximate and the other(s) as obviative. Dryer (1992, 1994) shows that in Kutenai there is a tendency to assign proximate status to one participant throughout a sequence of sentences (called proximate sequences), and this proximate status remains until any of various factors come into play to change it.

Lavukaleve's oia pronoun differs from this kind of system in a number of ways. Firstly, sentence boundaries are not relevant for oia. In addition, proximate/obviative assignment is fixed throughout a section of discourse; the speaker chooses which referent is to be which and they remain that way. By contrast, in Lavukaleve, the status of a participant, in terms of whether it should be referred to by oia or foia, is reassessed every time that participant, or other participants, are mentioned, clause by clause. As a corollary of this, oia is often used for alternately referring to different entities. Lastly, oia can be used, even when no other competing participant has been mentioned, to mean something like 'that one from before (who you might have forgotten about)'.

Obviation works by deliberately assigning prominence to a referent; out of all the participants in a discourse, the speaker uses the proximate form to tell the listener which one they should be most interested in. By contrast, Lavukaleve's system, rather than deliberately assigning prominence to a referent, instead reflects the level of activation or accessibility of a referent. These properties can be manipulated, but not overtly assigned.

Obviation systems tag the salience of a referent in order to assign that referent to a class and thence to track it. Foley \& Van Valin (1984: 339) point out the connection between obviation systems (which they call 4th-person systems) and gender: in obviation systems, like in gender systems, a noun is classified 
according to one of its features (in the case of obviation systems, its salience in the discourse). Its obviation status then becomes an agreement property; obviation, like gender, is a way of classifying nouns for the purposes of morphological encoding. The two systems differ in that gender is an inherent feature of a noun, whereas obviation is an assigned feature (Foley \& Van Valin 1984: 333). Cognitive status systems like that of Lavukaleve do not operate as a way of classifying referents in order to track them; rather, they work by tracking any referent of the appropriate status. The speaker and audience together work out the reference on a case-by-case basis. However, even though the functioning of the obviation systems is quite different from Lavukaleve's oia/foia distinction, and also from the tracking systems in Dutch and To'aba'ita, the fundamental principle is the same: these systems all track referents according to their cognitive status.

It seems useful to view obviation as one subtype of a cognitive status-based tracking system, of which Lavukaleve's oia/foia system and the systems in Dutch and To' aba'ita (and presumably other languages) are another subtype. In accordance with this, a revised version of Huang's (2000) typology of reference tracking systems is proposed, as follows:

TYPOLOGY OF MORPHOSYNTACTIC REFERENCE TRACKING

(i) gender system (tracks inherent feature of referent)

(ii) switch-reference system (tracks syntactic status of referent)

(iii) switch-function system (tracks semantic status of referent)

(iv) cognitive status system (tracks cognitive status of referent)

Note that this typology is one of morphosyntactically realised reference tracking systems: it does not include the category of inference systems which Foley \& Van Valin (1984) and Huang (2000) do include.

\section{Conclusions}

Lavukaleve's anaphoric reference system, with its two demonstrative pronouns oia and foia, is interesting for a number of reasons. Lavukaleve adds something to our understanding of the theoretical basis of reference tracking. The distinction between activated and nonactivated participants is widely attested, but that between semi-activated and activated participants has been posited largely on theoretical grounds. Lavukaleve presents evidence in support of the theory, in the form of grammaticalised pronouns expressing these categories. Various controlled experiments have been conducted to try to elicit linguistic reflexes of activation levels (e.g., Tomlin's 1995, 1997, etc. investigation of the linguistic correlates of attention in English by directly manipulating subjects' attention) but in Lavukaleve one can see in natural spontaneous data a system operating to 
express the categories of levels of activation as part of the basic morphosyntax of the language.

Furthermore, this type of reference tracking system has hitherto not been widely reported, and is not recognised in typologies either of demonstratives or of reference tracking. Gundel et al.'s (1993) work is an interesting exception to this, but has not been incorporated into the typological literature. The argument proposed here accords well with Gundel et al.'s work on the morphosyntactic realisations of differing levels of givenness. Evidence was presented from Lavukaleve and other languages which shows that existing typologies of reference tracking need to be extended to include languages which track referents according to their cognitive status. The relationship between such systems and obviation was explored, and a typology of reference tracking was suggested in which obviation is seen as a subtype of a reference tracking system which tracks referents according to their cognitive status.

Received: 5 September 2000

Revised: 13 February 2001

Max-Planck-Institut für evolutionäre Anthropologie

Correspondence address: Max-Planck-Institut für evolutionäre Anthropologie, Inselstr. 22, 04103 Leipzig, Germany; e-mail: terrill@eva.mpg.de Acknowledgments: Thanks to Patterson Barua, Mostin Nekuiga, James Nepolo, Clement Oiva, Honiara Resman, and Nicholas Sobo for providing the data cited in this paper. Thanks to Bernard Comrie, Matthew Dryer, Michael Dunn, Zygmunt Frajzyngier, Nikolaus Himmelmann, and three anonymous referees for reading and commenting on previous versions of this paper.

Abbreviations: ACT activated demonstrative pronoun (from foia paradigm), ANT anterior, ART definite article, CAUS causative, COMPL completive, DIST 1 distal, DIST2 unspecified distal, DU dual, DUR durative, EFOC focus marker from heo paradigm, EMPH emphatic, EX exclusive, EXT extended, F feminine, FOC focus marker from feo paradigm, HAB habitual, IMPF imperfective, IN inclusive, M masculine, MED medial, MOD demonstrative modifier (from hoia paradigm), N neuter, NEG negative, NF non-finite, O object, NP noun phrase, PCTIMP punctual imperative, PL plural, POSS possessive, POT potential, PRES present tense, PROX proximal, PSNV presentative, PSV possessor-subject verb, $S$ subject (both transitive and intransitive unless otherwise stated), SBD subordinate, SEMIACT semiactivated demonstrative pronoun (from oia paradigm), SG singular, SPEC specifier, SUCC successive, SURP surprise.

\section{References}

Ariel, Mira (1988). Referring and accessibility. Journal of Linguistics 24: 65-87.

Chafe, Wallace L. (1987). Cognitive constraints on information flow. In Russell S. Tomlin (ed.), Coherence and Grounding in Discourse, 21-51. Amsterdam: Benjamins. 


\section{Angela Terrill}

- (1994). Discourse, Consciousness and Time: The Flow and Displacement of Conscious Experience in Speaking and Writing. Chicago: Chicago University Press.

Comrie, Bernard (1989). Some general properties of reference-tracking systems. In Doug Arnold, Martin Atkinson, Jacques Durand, Claire Grover, \& Louisa Sadler (eds.), Essays on Grammatical Theory and Universal Grammar, 37-51. Oxford: Clarendon.

- (1997). Pragmatic binding: Demonstratives as anaphors in Dutch. Berkeley Linguistics Society 23: 50-61.

Diessel, Holger (1999). Demonstratives: Form, Function and Grammaticalization. Amsterdam: Benjamins.

Dryer, Matthew S. (1992). A comparison of the obviation systems of Kutenai and Algonquian. In William Cowan (ed.), Papers of the 23rd Algonquian Conference, 119-163. Ottawa: Carleton University.

- (1994). The discourse function of the Kutenai inverse. In Talmy Givón (ed.), Voice and Inversion, 65-99. Amsterdam: Benjamins.

- (1996). Focus, pragmatic presupposition, and activated propositions. Journal of Pragmatics 26: $475-523$.

Fillmore, Charles J. (1982). Towards a descriptive framework for spatial deixis. In Robert J. Jarvella \& Wolfgang Klein (eds.). Speech, Place, and Action, 31-59. Chichester: Wiley.

Foley, William A. \& Robert D. Van Valin, Jr. (1984). Functional Syntax and Universal Grammar. Cambridge: Cambridge University Press.

Fox, Barbara (ed.) (1996). Studies in Anaphora. Amsterdam: Benjamins.

Frantz, Donald G. (1991). Blackfoot Grammar. Toronto: University of Toronto Press.

Givón, Talmy (ed.) (1983). Topic Continuity in Discourse: A Quantitative Cross-language Study. Amsterdam: Benjamins.

Gundel, Jeanette K., Nancy Hedberg, \& Ron Zacharski (1993). Cognitive status and the form of referring expressions in discourse. Language 69: 274-307.

Heath, Jeffrey (1983). Referential tracking in Nunggubuyu (Australia). In John Haiman \& Pamela Munro (eds.), Switch Reference and Universal Grammar, 129-149. Amsterdam: Benjamins.

Himmelmann, Nikolaus P. (1996). Demonstratives in narrative discourse: A taxonomy of universal uses. In Fox (ed.), 205-254.

Huang, Yan (2000). Anaphora: A Cross-linguistic Study. Oxford: Oxford University Press.

Kibrik, Andrej (1996). Anaphora in Russian narrative prose: A cognitive calculative account. In Fox (ed.), 255-303.

Lichtenberk, Frantisek (1988). The pragmatic function of nominal anaphora in To'aba'ita. Studies in Language 12: 299-344.

- (1996). Patterns of anaphora in To'aba'ita discourse. In Fox (ed.) 379-411.

Terrill, Angela (1999). Lavukaleve: A Papuan language of the Solomon Islands. Doctoral dissertation, Australian National University.

Todd, Evelyn M. (1975). The Solomon language family. In Stephen A. Wurm (ed.), New Guinea Area Languages and Language Study, Volume 1: Papuan Languages and the New Guinea Linguistic Scene (Pacific Linguistics, C-38), 805-846. Canberra: Australian National University.

Tomlin, Russell S. (1995). Focal attention, voice and word order: An experimental cross-linguistic study. In Pamela Downing \& Michael Noonan (eds.), Word Order and Discourse, 517-554. Amsterdam: Benjamins.

- (1997). Mapping conceptual representations into linguistic representations: The role of attention in grammar. In Jan Nuyts \& Eric Pederson (eds.), Language and Conceptualization, 162-189. Cambridge: Cambridge University Press.

Watkins, Laurel J. (1990). Noun phrase versus zero in Kiowa discourse. International Journal of American Linguistics 56: 410-426.

Wurm, Stephen A. (1982). Papuan Languages of Oceania. (Ars Linguistica, 7.) Tübingen: Narr. 